\title{
High-Tech industry budget assessment and planning model
}

\author{
Evgenii Khrustalev ${ }^{1}$, Oleg Khrustalev ${ }^{1}$, Nina Baranova ${ }^{2, *}$, and Daria Loginova ${ }^{1,2}$ \\ ${ }^{1}$ Laboratory of simulation modeling and the interaction of economic objects, Central Economics and \\ Mathematics Institute RAS (CEMI RAS), Nakhimovsky prospect, 47, 117418 Moscow, Russia \\ ${ }^{2}$ Peoples' Friendship University of Russia (RUDN University), Miklukho-Maklaya Str, 6, 117198 \\ Moscow, Russia
}

\begin{abstract}
In the conditions of a constant budget deficit allocated to the research and manufacturing complex, the problem of value for money take on particular significance. The solution to this problem largely depends on the scientific validity of planning budget expenditures for innovative development and, first of all, on the optimality of the plans being developed in the context of crises, pandemics or sanctions. In this connection, the article analyzes modern research and manufacturing complex development processes under fiscal stress. As a result, economic and mathematical tools based on the analytic hierarchy process will be scientifically substantiated and developed. This method is designed to build a model that allows to quantify and efficiently distribute funds allocated by the State. This is necessary for the formation of that part of the budget item, which refers to the innovative development of knowledgebased industry.
\end{abstract}

\section{Introduction}

The efficiency disbursing public funds allocated to enterprises of the research and manufacturing complex (RMC), and the assessment of their contribution to the rate and quality of economic progress [1-4] cannot be assessed by a single indicator [5]. Even such an important indicator as the scientific and technological potential (scientific and technological capabilities) of individual enterprises and corporations of the RMC cannot serve as a sufficient measure for assessing the effectiveness. This is due to the fact that the pattern of this spending is characterized by interpenetration in various knowledge-intensive branch of the economy, as well as in the organization of the social sector, science and education [6]. In modern conditions of the rapid growth of knowledge-intensive industries and high-tech progress, in a context of uncertainty associated with a pandemic, crisis, etc., the efficient spending of funds is determined not so much by the value of the potential scientific and technical capabilities of the RMC, but in the indicator (indicators) characterizing its survival (structural, staff, etc.) and subsequent regeneration [7]. Thus, it is imperative to develop and apply multi-criteria optimization and tool method, which is

\footnotetext{
* Corresponding author: baranova_nm@pfur.ru
} 
currently formalized and poorly and ill-defined, in order to formulate a strong mathematical problem to optimize a complex system of existing norms for disbursing public funds.

However, when identifying the dependences of the efficiency of spending the allocated resources, fundamental difficulties were identified. The fact of the matter is that these dependencies are so complex that their identification is possible in most cases only by parameterization based on extremely complex simulation models [8]. It is possible to apply the existing models to assess the impact on scientific and technical potential only for certain types of resources, but these models are not applicable for the majority, and special ones have not been developed. Moreover, there are no simulation models for other indicators of the resource use efficiency.

Thus, the objective function of the optimization problem of resource use in the form of an explicit, analytically specified function of the controlled parameters could not be represented. This circumstance determines the need to improve the processes of financial planning in the field of knowledge-intensive industries [9-10].

\section{Materials and Methods}

The proceedings of world scientists Astashova N. [1], Baranova N.M. [2, 10], Shevtsova N.A., Dmitrieva E.G. [2], Pilipenko A.I., Dikhtiar V.I., Pilipenko Z.A. [10], Sukharev O.S. [3], Sydor I.P., Koval S.L. [4], Tishutina O.I., Mikhailov A.V. [5], Tedeeva Z.B., Kulova A.Z. [6], Zimarin K.A., Zakirova Yu.A. [7], Canay I.A., Shaikh A.M. [8], Khrustalev E.Yu., Strelnikova I.A. [9], Saaty Thomas L. [11-14], Kearns K. [11], Blanchard O., Gopinath G., Rogoff K. [15], Zhang L. [16], Gómez M.A. [17], Crainich D., Eeckhoudt L., Le Courtois O. [18], Menegatti M., Peter Richard [19], Gollier C. [20] were studied to solve the problem. As a result, an optimization model was developed using the analytic hierarchy process. The proposed model will make it possible to effectively distribute allot funds for the development of science-intensive industries.

\section{Results and Discussion}

\subsection{Building an objective function using the analytic hierarchy process}

Despite the problems that arose in the formulation and solution of the optimization problem of the disbursing public funds for the development of science-intensive industries, it turned out to be possible to present the objective function in a different way. The analytic hierarchy process has already been sufficiently tested and can be proposed as one of the methods for the formalized construction of a linearized objective function [11-13]. This method involves the sequential decomposition of the global (generalized) objective function into its individual criterion components and the processing of expert judgements about them using the pairwise comparisons.

The essence of using the method of detailed analytic hierarchy process in the sequential calculation of the values of global and particular priorities, and then in checking the degree of consistency of the results obtained at each analyzed stage. The calculation of these vectors is based on the construction of matrices of paired comparisons of all criterial components of each hierarchical level and on the execution of a certain specific sequence of operations on them. These operations are performed for all existing hierarchical levels [14]. At the last level, the vectors of resource priorities are determined, and the degree of their impact on the criterial components of the penultimate (previous) level is also revealed.

The weighing coefficients $\boldsymbol{K}_{\boldsymbol{i}}$ for each considered particular criterion are considered by an expert and established the preference pattern chosen by him. The coordinated (i.e., 
logically consistent) priorities of each selected particular criterion are established to determine $\boldsymbol{K}_{i}$ by pairwise comparison of them on a certain scale of relative importance.

In practice, it is the following scale of relative importance in pairwise comparison that has become widespread:

1 - equal importance of resources;

3 - weak importance for one resource over another;

5 - essential or strong importance of one resource over another;

7 - demonstrated importance of one resource over another;

9 - absolute importance of one resource over another;

$\mathbf{2}, \mathbf{4 , 6}, \mathbf{8}$ - intermediate values between the two adjacent judgments.

Using this scale, the inverse of symmetric square matrices of all paired comparisons made are constructed for each particular criterion at all levels and resources at the final (last) level (1) [13]:

$$
\left\|a_{i j}\right\|,\left(a_{i j}=\frac{1}{a_{j i}}\right)
$$

$i=1 \ldots n ; j=1 \ldots n-$ the number of criteria (or resources) compared at each level.

A set of local priorities is determined from the formed groups of matrices of pairwise comparisons, which express $\boldsymbol{K}_{\boldsymbol{i}}$. The determination of $\boldsymbol{K}_{\boldsymbol{i}}$ is based on the calculation of the eigenvectors of the obtained matrices, their normalization and consistency check. So, $\boldsymbol{K}_{\boldsymbol{i}}$ are calculated as follows for the criteria of the first level of the hierarchy.

The weights are assigned for each criterion of the first level (2), in accordance with the used preference scale, and a matrix of pairwise comparisons $\left\|a_{i j}\right\|$ is constructed.

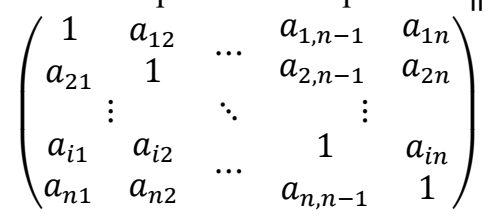

Next, the components of the eigenvector of the matrix are calculated (3):

$$
a_{1}=\sqrt[n]{\prod_{j}^{n} a_{1 j}} ; \cdots ; a_{n}=\sqrt[n]{\prod_{j}^{n} a_{n j}}
$$

Then, the normalized estimates of the local priority vectors of the first level are determined:

$$
K_{1}=\frac{a_{1}}{\sum_{i} a_{i}} ; \cdots ; K_{n}=\frac{a_{n}}{\sum_{i} a_{i}}
$$

Finally, the consistency of the obtained local priorities is checked by calculating the consistency index (CI) and comparing it with random consistency (5):

$$
\mathrm{CI}=\frac{\sum_{i=1}^{n} K_{i} \sum_{j=1}^{n} a_{i j}-n}{n-1}
$$

If the CI is no more than $10-15 \%$, the obtained $\boldsymbol{K}_{i}$ values are considered to be sufficiently consistent [12], otherwise the expert should carefully check and clarify the preferences assigned to him. The similar operations are performed at all levels of the hierarchy. It provides to determine all the values of the weighing coefficients for each parameter of the last (lower) level. These values will be the final priority of each specific normalized resource for a linear objective function [11-14].

\subsection{The principles for constructing a mathematical model}

Let us consider the proposed method in the context of solving a task of reducing financial exposure [9-10, 18-19] and determining the rational volume of funding cuts for the main 
object of expenditure on the development of high-tech industries while limiting the state budget of the RMC.

The objective function should be constructed to solve this problem and the degree of influence on it by each of the object of expenditure on the development of high-tech industries should be assessed. In this case, the main objects of expenditure are the types of normalized resources for which the unconditional specific consumption indicator is known (in this case, the annual consumed amount of financing). Not absolute values of these indicators will be used, but relative values (expressed as a percentage of needs). The task can be reformulated: to determine the most rational percentage of satisfaction of needs for each item of expenditure in the conditions of a given funding deficit.

As noted, there is no explicit objective function for determining the effective disbursing public funds. Therefore, we will make the assumption that the objective function will take the maximum value, i.e. equal to 1 , with $100 \%$ satisfaction of needs for all objects of expenditure. Let us construct the given objective function by the analytic hierarchy process. In order to do this, build a three-level hierarchy:

the 0 level corresponds to making decisions across the entire vector of target priorities;

the 1 st level corresponds to the components of the vector of target priorities;

the 2 nd level corresponds to the components of the priority vector of expenditure items.

The main problem that arises when determining the objective function is the decomposition of ideas about the efficiency of disbursing public funds into simpler components. It means a sequence of judgments is formed by the person making a decision on the priority of standardized items of expenditure in terms of their impact on the total efficiency. Therefore, the main stage will be the building of a hierarchy of judgments between the 0 and last levels (in this case, this is only one, 1 st level).

The task of presenting judgments of the 1 st level is the formulation of priority goals to be achieved as a result of disbursing allocated public funds, their ranking according to the degree of importance by the decision maker. The task of formulating goals is solved on the basis of an assessment of the totality of political, economic, social and other factors in the current timeframe.

Let us define the priority vector of the 1 st level of the hierarchy through a set of ranked goals [9].

The number of the RMC employees (the priority of $\boldsymbol{K}_{l}$, determines the importance of maintaining the existing staff number).

The scientific and technical potential level of the RMC (the priority of $\boldsymbol{K}_{2}$, determines the importance of the average level of innovativeness of the RMC enterprises).

The qualification of the RMC key personnel and the science intensity of the RMC production capacity (the priority of $\boldsymbol{K}_{3}$ ).

The conversion of spending on the RMC development in solving social and economic problems of the state (the priority of $\boldsymbol{K}_{4}$ ).

$\boldsymbol{K}_{i}$ is an alternative set of goals that a decision-maker wants to achieve in the process of spending the limited financial resources allocated to him.

The absolute priority of $\boldsymbol{K}_{\boldsymbol{1}}$ means that the number of the RMC employees affects the ability of the state to create innovative science-intensive and high-tech products. The absolute priority of $\boldsymbol{K}_{2}$ means "less is more". The priority of $\boldsymbol{K}_{3}$ means "the main thing is to survive, preserving the most valuable until better times". The priority of $\boldsymbol{K}_{4}$ means that public funds should be used as much as possible to offset the costs of social (non-scientific) programs.

Obviously, the absolute priority of one of $\boldsymbol{K}_{\boldsymbol{i}}$ cannot be chosen as a solution, however, none of $\boldsymbol{K}_{\boldsymbol{i}}$ can be completely ruled out. Therefore, the solution will be a balanced set of $\boldsymbol{K}_{i}$, which determines the priority vector. 


\subsection{The priority vector}

The method of pairwise comparisons of the analytic hierarchy process is used to determine such a priority vector [11-14]. It can be used to process the judgments of experts on the priorities of the considered alternatives $\boldsymbol{K}_{i}$.

Comparing the pairwise presented alternatives $\boldsymbol{K}_{\boldsymbol{i}}$, the expert, at his own discretion, determines the preference pattern and assigns a certain point to each of them on a scale of relative importance. As a result, this preference pattern will represent an inverse of symmetric square matrix, its dimension is $4 \times 4$ (Table 1 ).

The processing this matrix using the formulas (1)-(5) makes it possible to calculate the priority vector of goals. The components of this vector determine the degree of their importance from the point of view of an expert. In this case, the preferences established by the expert will be as follows:

$\boldsymbol{K}_{\boldsymbol{1}}=0,088$ - the number of the RMC employees;

$\boldsymbol{K}_{2}=0,255-$ the scientific and technical potential level;

$\boldsymbol{K}_{3}=0,540-$ the qualification of the RMC key personnel;

$\boldsymbol{K}_{4}=0,117-$ the conversion of spending on the RMC development.

Table 1. The preference pattern.

\begin{tabular}{|l|c|c|c|c|}
\hline \multicolumn{1}{|c|}{$\begin{array}{c}\text { The } \\
\text { number of } \\
\text { the RMC } \\
\text { employees, } \\
\boldsymbol{K}_{\boldsymbol{1}}\end{array}$} & $\begin{array}{c}\text { The } \\
\text { scientific } \\
\text { and } \\
\text { technical } \\
\text { potential } \\
\text { level, } \boldsymbol{K}_{2}\end{array}$ & $\begin{array}{c}\text { The } \\
\text { qualification } \\
\text { of the RMC } \\
\text { key } \\
\text { personnel, } \\
\boldsymbol{K}_{3}\end{array}$ & $\begin{array}{c}\text { The } \\
\text { conversion of } \\
\text { spending on } \\
\text { the RMC } \\
\text { development, } \\
\boldsymbol{K}_{4}\end{array}$ \\
\hline $\begin{array}{l}\text { The number of the } \\
\text { RMC employees, } \\
\boldsymbol{K}_{1}\end{array}$ & 1 & $1 / 3$ & $1 / 4$ & $1 / 2$ \\
\hline $\begin{array}{l}\text { The scientific and } \\
\text { technical potential } \\
\text { level, } \boldsymbol{K}_{2}\end{array}$ & 3 & 1 & $1 / 3$ & 3 \\
\hline $\begin{array}{l}\text { The qualification } \\
\text { of the RMC key } \\
\text { personnel, } \boldsymbol{K}_{3}\end{array}$ & 4 & 3 & 1 & 5 \\
\hline $\begin{array}{l}\text { The conversion of } \\
\text { spending on the } \\
\text { RMC development, } \\
\boldsymbol{K}_{4}\end{array}$ & 2 & $1 / 3$ & $1 / 5$ & 1 \\
\hline
\end{tabular}

The consistency check of these expert judgments shows that CI equals 0.0533 $(\mathrm{CI}<10 \%)$. Having determined the priority vector of the $1^{\text {st }}$ level, construct the priority vectors of the $2^{\text {nd }}$ level. To achieve this, define the degree of influence of each of the expense items on each component of the target priority vectors of the previous level. Since in this case the target priority vectors contain four components and five items of expenditure are considered (the $\mathrm{R} \& \mathrm{D}\left(k_{j}^{l}\right)$, advanced vocational training $\left(k_{j}^{2}\right)$, the RMC staff costs $\left(k_{j}^{3}\right)$, procurement of innovative equipment $\left(k_{j}^{4}\right)$, infrastructure development $\left(k_{j}^{5}\right)$, it is possible to build and process 4 matrices of pairwise comparisons (its dimensions will be $5 \times 5)$.

1. The vector of the significance of cost item for the number of the RMC employees.

The degree of influence of cost item on the target factor "The number of the RMC employees" based on the results of processing the matrix is determined by the following components of the normalized eigenvector of the matrix:

$k_{l}^{l}=0,100$ - the item of "R\&D expenditures";

$k_{l}^{2}=0,302-$ the item of "advanced vocational training";

$k_{l}^{3}=0,490$ - the item of "the RMC staff costs"; 
$k_{l}^{4}=0,133$ - the item of "procurement of innovative equipment";

$k_{l}^{5}=0,045$ - the item of "infrastructure development".

The consistency index $\boldsymbol{C I}_{\boldsymbol{1}}$ equals 0,033 . level.

2. The vector of the significance of cost item for the scientific and technical potential

The degree of influence of cost item on the target factor "The scientific and technical potential level" based on the results of processing the matrix is determined by the following components of the normalized eigenvector of the matrix:

$k_{2}^{l}=0,234-$ the item of "R\&D expenditures";

$k_{2}^{2}=0,302-$ the item of "advanced vocational training";

$k_{2}^{3}=0,061$ - the item of "the RMC staff costs";

$k_{2}^{4}=0,292$ - the item of "procurement of innovative equipment";

$k_{2}^{5}=0,109$ - the item of "infrastructure development".

The consistency index $\boldsymbol{C I}_{2}=0,028$.

3. The vector of the significance of cost item for the qualification of the RMC key personnel.

The degree of influence of cost item on the target factor "The qualification of the RMC key personnel" based on the results of processing the matrix is determined by the following components of the normalized eigenvector of the matrix:

$k_{3}^{l}=0,259$ - the item of "R\&D expenditures";

$k_{3}^{2}=0,250$ - the item of "advanced vocational training";

$k_{3}^{3}=0,259$ - the item of "the RMC staff costs";

$k_{3}^{4}=0,158$ - the item of "procurement of innovative equipment";

$k_{3}^{5}=0,074-$ the item of "infrastructure development".

The consistency index $\boldsymbol{C I}_{3}=0,021$.

4. The vector of the significance of cost item for the conversion of spending on the RMC development.

The degree of influence of cost item on the target factor "The conversion of spending on the RMC development" based on the results of processing the matrix is determined by the following components of the normalized eigenvector of the matrix:

$k_{4}^{l}=0,126$ - the item of "R\&D expenditures";

$k_{4}^{2}=0,055$ - the item of "advanced vocational training";

$k_{4}^{3}=0,155$ - the item of "the RMC staff costs";

$k_{4}^{4}=0,235$ - the item of "procurement of innovative equipment";

$k_{4}^{5}=0,429$. - the item of "infrastructure development".

The consistency index $\boldsymbol{C I}_{4}=0,087$.

\section{Conclusions}

Having received the values of $\boldsymbol{K}_{\boldsymbol{i}}$ and $k_{j}^{i}$, the weight coefficients in linear form can be determine and the objective function could be written (6):

$$
\begin{aligned}
& F(x 1, x 2, x 3, x 4, x 5)=\sum_{i=1}^{5} b_{j} \cdot x_{j} \rightarrow \max \\
& b_{j}=\sum_{i} K_{i} \cdot k_{j}^{i}, \quad 0<x_{j}<1
\end{aligned}
$$

In this case, the objective function becomes as follows (7):

$$
F\left(x_{1}, x_{2}, x_{3}, x_{4}, x_{5}\right)=0.21 \cdot x_{1}+0.24 \cdot x_{2}+0.19 \cdot x_{3}+0.24 \cdot x_{4}+0.12 \cdot x_{5}
$$

$\boldsymbol{x}_{\boldsymbol{j}}$ - the percentage of satisfaction of needs under the relevant item of expenditure. 
It is possible to determine the best values of $x_{1}, x_{2}, x_{3}, x_{4}, x_{5}$ to achieve the maximum of the objective function using mathematical programming methods or, for example, using the MS Excel program (via the Solver Tool add-in).

To conclude, the considered case of reducing financial exposure and determining the level of funding for the development of high-tech industries while limiting the state budget of the RMC illustrates the practical application of this approach. The proposed model is universal and can be used by any country to plan budgetary expenditures for the development of science-intensive industries.

\section{References}

1. N. Astashova, Int. J. Management Theory and Practice, 8, 19 (2011)

2. N. M. Baranova, N. A. Shevtsova, E. G. Dmitrieva, GCPMED2018, 1, 1877, (2019)

3. O. S. Sukharev, Financial J., 1, 17 (2015)

4. I. P. Sydor, L. Koval, Scientific-Theoretical J. «Science and Economics», 3, 18 (2014)

5. O. I. Tishutina, A. V. Mikhailov, J. Problems of Modern Economics, 4, 194 (2012)

6. Z. B. Tedeeva, A. Z. Kulova, J. Science: Society Economy Law, 1, 62 (2020)

7. K. A. Zimarin, Yu. A. Zakirova, J. Science. Education. Economy. Series: Economy, 3, $6(2013)$

8. I. A. Canay, A. M. Shaikh, Advances in economics and econometrics: Eleventh world congress, 2, 271 (2017)

9. E. Yu. Khrustalev, I. A. Strelnikova, J. Finance and Credit, 7, 13 (2011)

10. A. I. Pilipenko, V. I. Dikhtiar, N. M. Baranova, Z. A. Pilipenko, Modeling Economic Growth in Contemporary Russia, 63 (2019)

11. T. L. Saaty, K. Kearns, Analytical Planning. The Organization of Systems (1985)

12. T. L. Saaty, Int. J. Services Sciences, 1 (2008)

13. T. L. Saaty, Mathematical Principles of Decision Making (2010)

14. T. L. Saaty, Cloud of Science, 1 (2015)

15. O. Blanchard, G. Gopinath, K. Rogoff, IMF Econ Rev, 69, 258 (2021)

16. L. Zhang, J. Econ, 115, 73 (2015)

17. M. A. Gómez, J. Econ., 117, 37 (2016)

18. D. Crainich, L. Eeckhoudt, O. Le Courtois, J. Math. Econ., 88, 153 (2020)

19. M. Menegatti, R. Peter, SSRN (2020)

20. C. Gollier, Toulouse School of Economics Working Paper, 19, 1003 (2019) 